\title{
Pulmonary infection control window as a switching point for sequential ventilation in the treatment of COPD patients: a meta-analysis
}

This article was published in the following Dove Press journal:

International Journal of COPD

24 April 2017

Number of times this article has been viewed

Yingying Lv*

Qiurong Lv*

Quanchao Lv

Tianwen Lai

Department of Respiratory and Critical Care Medicine, The Affiliated

Hospital, Institute of Respiratory

Diseases, Guangdong Medical

University, Zhanjiang, China

*These authors contributed equally to this work
Correspondence: Tianwen Lai Department of Respiratory and Critical Care Medicine, The Affiliated Hospital, Institute of Respiratory Diseases, Guangdong Medical University, 57 Wenming Road, Zhanjiang, 52400 I, China

Email laitianwen20II@I63.com
Purpose: Choosing the appropriate time to switch to noninvasive positive-pressure ventilation (NPPV) plays a crucial role in promoting successful weaning. However, optimal timing for transitioning and weaning patients from mechanical ventilation (MV) to NPPV has not been clearly established. In China, the pulmonary infection control (PIC) window as a switching point for weaning from MV has been performed for many years, without definitive evidence of clinical benefit. This study aimed to summarize the evidence for NPPV at the PIC window for patients with respiratory failure from COPD.

Methods: A comprehensive search for randomized controlled trials (RCTs) was performed. The trials were all parallel studies comparing the PIC window weaning strategy versus conventional weaning strategy in treatment of patients with respiratory failure due to COPD.

Results: Sixteen studies of 647 participants were eligible. When compared with conventional weaning strategy, early extubation followed by NPPV at the point of PIC window significantly reduced the mortality rate (risk ratios [RRs] $0.36,95 \%$ confidence interval [CI] 0.23 to 0.57 ) and ventilator-associated pneumonia (VAP) (RR $0.28,95 \%$ CI 0.19 to 0.41 ); it also decreased the duration of invasive ventilation (weighted mean difference [WMD] -7.68 days, 95\% CI -9.43 to -5.93 ) and total duration of ventilation (WMD -5.93 days, $95 \% \mathrm{CI}-7.29$ to -4.58 ), which also shortened the lengths of stay in an intensive care unit (WMD -8.51 days, 95\% CI - 10.23 to -6.79 ), as well as length of stay in hospital (WMD -8.47 days, $95 \% \mathrm{CI}-8.61$ to -7.33 ).

Conclusion: The results showed that the PIC window as a switching point for sequential ventilation in treatment of respiratory failure in COPD patients may be beneficial. It might yield not only relevant information for caregivers in China but also new insights for considering the PIC window by physicians in other countries.

Keywords: mechanical ventilation, ventilator-associated pneumonia, weaning, acute exacerbation, spontaneous breathing trial, intensive care unit

\section{Introduction}

COPD remains a major public health problem. It is the fourth leading cause of chronic morbidity and mortality in the US and is projected to rank fifth in 2020 in disease caused throughout the world. ${ }^{1}$ In China, respiratory diseases (of which COPD is a significant component) are the third leading cause of death in rural areas and the fourth leading cause of death in urban areas, accounting for 1 million deaths and over 5 million disabilities each year. ${ }^{2}$ Approximately $80 \%$ of COPD exacerbates due to pulmonary infection, as well as some severe respiratory failure often requiring endotracheal intubation (ETI) and mechanical ventilation (MV). ${ }^{3}$ ETI and MV can help to drain sputum and reduce the respiratory workload, partially or even completely, 
so as to control bronchial pulmonary infection. Respiratory muscle fatigue, hyperinflation, and malnutrition are common in COPD patients, which may require prolonged MV. ${ }^{3}$ Prolonged MV has been associated with the development of complications, for example, upper airway pathology, sinusitis, and ventilator-associated pneumonia (VAP). VAP is associated with increased morbidity and mortality of VAP in the intensive care unit (ICU), which would be $\sim 30 \%$ or higher. ${ }^{4}$ Minimizing the duration of artificial airway placement is an important goal of critical care.

Early withdrawal of invasive MV (IMV) followed by noninvasive positive-pressure ventilation (NPPV) is a new strategy for avoiding or reducing the duration of invasive mechanical support for intubated patients with respiratory failure. Choosing an appropriate time to transfer from IMV to NPPV is the key for performing sequential MV successfully. The invasive-noninvasive sequential ventilation defined as early extubation is conducted before conventional criteria for weaning and followed by NPPV. To neglect or delay the switching point for sequential ventilation can certainly miss the optimal opportunity. ${ }^{3}$ However, the appropriate switching point has been controversial. So far, no generally accepted boundary for a standard switch point has been defined.

In clinical practice, the pulmonary infection control (PIC) window has been the switch point for transferring from IMV to NPPV, so the time for early extubation can be more accurately judged; improved therapy efficacy was achieved by Wang et al. When the PIC window occurs, a patient's condition will become stable and improved if ventilation support is provided, especially for measures to resolve fatigue to the respiratory muscles. ${ }^{3}$ Timely extubation followed by NPPV with the appearance of the PIC window could manage the problem of patient's fatigue involving respiratory muscles and ventilator insufficiency simultaneously, thereby avoiding lower airway infection and VAP. In China, the PIC window has been used as the switching point for sequential ventilation in the treatment of COPD respiratory failure exacerbation for many years, despite the lack of definitive evidence of clinical benefit.

Moreover, the conclusions of these trials are inconsistent, so that the safety of this intervention remains uncertain. In order to comprehensively estimate the efficacy and safety of this weaning strategy, a systematic review and metaanalysis were conducted to summarize and analyze the results of randomized controlled trials (RCTs), comparing the PIC window weaning strategy versus the conventional weaning strategy in the treatment of patient with respiratory failure due to COPD. This meta-analysis suggests that the PIC window as a switching point for sequential ventilation could significantly reduce mortality, VAP, length of ICU and hospital stay, and duration of MV compared to conventional weaning strategy.

\section{Methods}

This systematic review was performed according to the PRISMA (Preferred Reporting Items for Systematic Reviews and Meta-Analyses) guidelines. ${ }^{5}$

\section{Criteria for the PIC window}

The standard of the PIC window was determined by the following items: 1) significantly decreased radiographic infiltrations; 2) significantly reduced quantity of sputum, thinning, and decreased density of sputum; 3) at least one of these accompanying signs: body temperature decreased to $<37.5^{\circ} \mathrm{C}$, leukocyte count $<10 \times 10^{9} / \mathrm{L}$ or $2 \times 10^{9} / \mathrm{L}$ less than before; and 4) adjustment of ventilator settings to 10-12 times per minute for synchronous intermittent mechanical ventilation (SIMV) and 10-12 $\mathrm{cmH}_{2} \mathrm{O}\left(1 \mathrm{cmH}_{2} \mathrm{O}=0.0198 \mathrm{kPa}\right)$ for pressure support ventilation (PSV).

\section{Search strategy}

This study aimed to identify all RCTs to assess the efficacy of PIC in the treatment of patients with respiratory failure due to COPD exacerbation. The electronic search strategy applied standard filters for the identification of RCTs. The following databases were searched: MEDLINE, EMBASE, Cochrane databases, Chinese electronic databases (eg, Wan Fang Database), CNKI (China National Knowledge Infrastructure) Database, and Current Controlled Trials from its inception to February 2016. The search included the following: pulmonary infection control window; continuous positive airway pressure; bilevel positive airway; non-invasive ventilation; COPD; lung disease; pulmonary disease; airway obstruction; obstructive pulmonary disease; emphysema; acute exacerbation; respiratory failure linked with RCT OR controlled clinical trial, in various combinations. There were no limits regarding the language of publication. Cross-references from original articles and reviews were checked, and sometimes authors were contacted to obtain additional unpublished data. Similarly a search of relevant trials from the clinical trial registry was performed to identify the existence of unpublished data. Trials published solely in abstract form were excluded.

\section{Selection of studies}

The specific inclusion criteria were as follows: 1) COPD exacerbation due to pulmonary infection; 2) receiving IMV due to respiratory failure; 3 ) the PIC window appearing after antibiotic use, IMV, and comprehensive therapy; 4) RCTs 
comparing the PIC window as a weaning strategy (extubation and NPPV via face or nasal mask, immediately upon appearance of the PIC window) versus the conventional weaning strategy (IMV was received continuously after the PIC window by using the conventional weaning technique); and 5) primary outcomes: mortality during hospital admission, VAP; secondary outcome measures: length of ICU stay, length of hospital stay, duration of MV, and adverse events associated with weaning.

\section{Data collection and quality assessment}

Initial selection was performed by distributing references among pairs of independent reviews. Titles and abstracts were independently reviewed by two reviewers (YYL and QCL) to identify their potential relevance for further assessment. Data from all the studies included in this analysis were obtained during the end of extension phases of the trial. Any disagreement appeared during the process was resolved through discussion and team consensus. In the case of unpublished reports or multiple published data, the most recent versions were extracted. After obtaining the full text, the authors independently assessed all the studies for inclusion based on the predefined criteria. If studies had partly overlapped subjects, the one with a larger sample size was selected. The quality of each trial was evaluated by using the Cochrane five-risk of bias domains tool. ${ }^{6}$

\section{Data analysis}

For dichotomous outcomes, risk ratios (RRs) with 95\% CI were calculated. For continuous outcomes, a weighted mean difference (WMD) and 95\% CI were calculated. $I^{2}$ values of $\geq 50 \%$ indicated a substantial level of heterogeneity. ${ }^{7}$ When found, a sensitivity analysis was performed to determine the source of heterogeneity. Subgroup analyses were conducted, and the meta-analysis was reanalyzed, including risk of bias (low vs high), sample size ( $\leq 40$ vs $>40$ ), disease severity (moderate vs severe respiratory failure), and experimental strategy (face mask vs face/nasal mask). Publication bias was carried out by the funnel plot and assessed by Egger's test. ${ }^{8}$ All the analyses were performed with Review Manager (Version 5.1, The Cochrane Collaboration, Copenhagen, Denmark) and Stata (Version 12.0; Stata Corporation, College Station, TX, USA). A $P$-value of $<0.05$ was considered to be statistically significant.

\section{Results \\ Study selection}

The electronic database search identified 454 citations. Of these, the first screening excluded 403 citations based on abstracts or titles, leaving 51 articles for full-text review. In these articles, 29 studies were excluded due to lack of relative outcomes and nonrandomized controls. After a detailed review, 6 studies were excluded: 2 for duplicated publications and 4 for did not evaluating NPPV in COPD patients. Thus, 16 trials were included in the meta-analysis, ${ }^{3,9-23}$ with detailed steps of the study selection process shown in Figure 1.

\section{Study description}

The level of PSV, the respiratory rate of SIMV, and tidal volume needed adjustment according to the patient's durability, ventilation, and blood gas analysis in all trials. During MV, comprehensive therapy was performed: including administration of antibiotics, dissolution of sputum, drainage of airway secretion, dilatation of bronchi, recovery of electrolyte disturbance, and nutrient support. Once the PIC window had appeared, each patient was randomly assigned to the noninvasive ventilation (NIV) group or the control group. All the trials compared NPPV with conventional MV therapy using full face masks. However, nasal masks were also used in 5 trials. ${ }^{13,14,20-23}$ The continuous positive airway pressure in these trials ranged from 3.5 to $12.0 \mathrm{cmH}_{2} \mathrm{O}$. The inspiratory positive airway pressure ranged from 14.5 to $20 \mathrm{cmH}_{2} \mathrm{O}$, and expiratory positive airway pressure was set at $5 \mathrm{cmH}_{2} \mathrm{O}$ in most trials. The main study characteristics are summarized in Table 1. In general, the methodological quality was acceptable. All the trial reports described the use

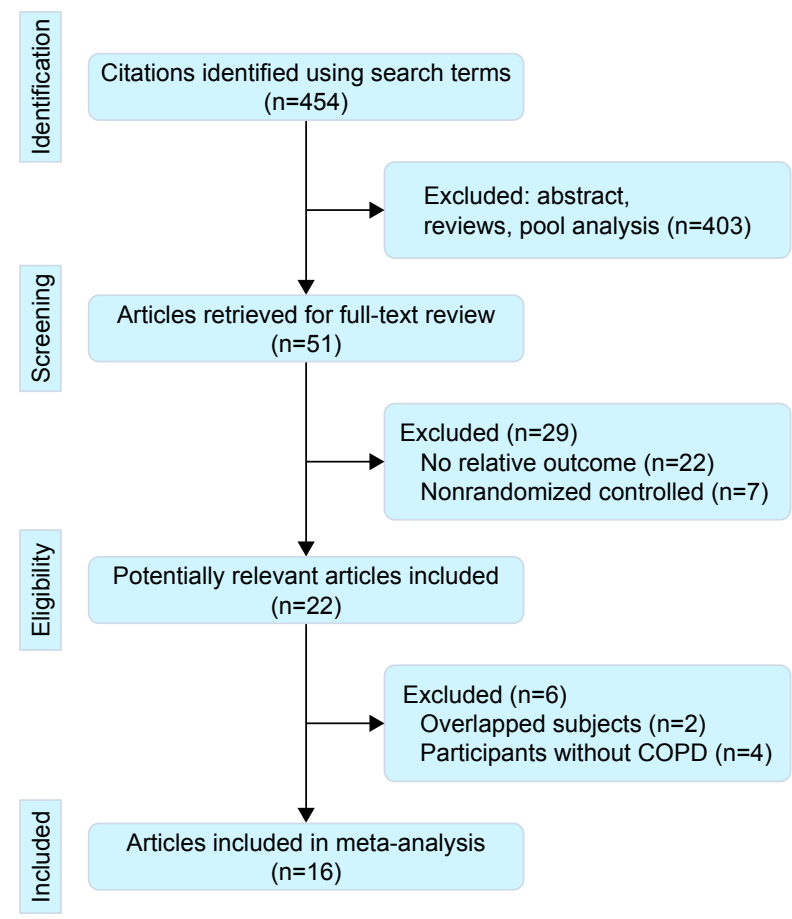

Figure I Flow diagram showing the selection process of material from identification to inclusion. 
Table I Characteristics of included studies

\begin{tabular}{|c|c|c|c|c|c|}
\hline Source & $\begin{array}{l}\text { Sample } \\
\text { size }\end{array}$ & $\begin{array}{l}\text { Age }^{\ddagger} \\
\text { (years) }\end{array}$ & Inclusion criteria & $\begin{array}{l}\text { Intubation } \\
\text { criteria }\end{array}$ & $\begin{array}{l}\text { Experimental } \\
\text { strategy }\end{array}$ \\
\hline Chen et $\mathrm{al}^{9}$ & 37 & NA & $\begin{array}{l}\text { AECOPD with pulmonary } \\
\text { infection, respiratory failure }\end{array}$ & Yes & $\begin{array}{l}\text { Bilevel NPPV delivered } \\
\text { by face mask }\end{array}$ \\
\hline Chen $^{10}$ & 30 & 65 & $\begin{array}{l}\text { AECOPD with respiratory failure, } \\
\text { pulmonary infection }\end{array}$ & Yes & $\begin{array}{l}\text { Bilevel NPPV delivered } \\
\text { by face mask }\end{array}$ \\
\hline $\begin{array}{l}\text { Jiang and } \\
\text { Jiang" }\end{array}$ & 46 & 60 & $\begin{array}{l}\text { AECOPD with severe respiratory } \\
\text { failure, pulmonary infection }\end{array}$ & Yes & $\begin{array}{l}\text { Bilevel NPPV delivered } \\
\text { by face mask }\end{array}$ \\
\hline $\mathrm{Li}$ and Zhou'2 & 40 & NA & $\begin{array}{l}\text { AECOPD with bronchopulmonary } \\
\text { infection, respiratory failure }\end{array}$ & Yes & $\begin{array}{l}\text { Bilevel NPPV delivered } \\
\text { by face mask }\end{array}$ \\
\hline Li et al ${ }^{13}$ & 41 & 69 & $\begin{array}{l}\text { AECOPD with severe respiratory } \\
\text { failure, pulmonary infection }\end{array}$ & Yes & $\begin{array}{l}\text { Bilevel NPPV delivered } \\
\text { by face or nasal mask }\end{array}$ \\
\hline Lin et $\mathrm{a}^{14}$ & 32 & 61.5 & $\begin{array}{l}\text { AECOPD with severe respiratory } \\
\text { failure, pulmonary infection }\end{array}$ & Yes & $\begin{array}{l}\text { Bilevel NPPV delivered } \\
\text { by face or nasal mask }\end{array}$ \\
\hline Lun et $\mathrm{al}^{15}$ & 36 & 71 & $\begin{array}{l}\text { AECOPD with bronchopulmonary } \\
\text { infection, respiratory failure }\end{array}$ & Yes & $\begin{array}{l}\text { Bilevel NPPV delivered } \\
\text { by face mask }\end{array}$ \\
\hline Ning et $\mathrm{al}^{16}$ & 28 & 62.4 & $\begin{array}{l}\text { AECOPD with respiratory failure, } \\
\text { pulmonary infection }\end{array}$ & Yes & $\begin{array}{l}\text { Bilevel NPPV delivered } \\
\text { by face mask }\end{array}$ \\
\hline Wang et al ${ }^{17}$ & 11 & 64.8 & $\begin{array}{l}\text { AECOPD with bronchopulmonary } \\
\text { infection, respiratory failure }\end{array}$ & Yes & $\begin{array}{l}\text { Bilevel NPPV delivered } \\
\text { by face mask }\end{array}$ \\
\hline Wang $^{3}$ & 90 & 67.6 & $\begin{array}{l}\text { AECOPD with severe respiratory } \\
\text { failure, pulmonary infection }\end{array}$ & Yes & $\begin{array}{l}\text { Bilevel NPPV delivered } \\
\text { by face mask }\end{array}$ \\
\hline Wu et $a^{18}$ & 28 & NA & $\begin{array}{l}\text { AECOPD with respiratory failure, } \\
\text { pulmonary infection }\end{array}$ & Yes & $\begin{array}{l}\text { Bilevel NPPV delivered } \\
\text { by face mask }\end{array}$ \\
\hline Zhang et a $\left.\right|^{19}$ & 30 & 66.9 & $\begin{array}{l}\text { AECOPD with severe respiratory } \\
\text { failure, pulmonary infection }\end{array}$ & Yes & $\begin{array}{l}\text { Bilevel NPPV delivered } \\
\text { by face mask }\end{array}$ \\
\hline $\begin{array}{l}\text { Zhang and } \\
\text { Zhao } 20\end{array}$ & 48 & 73 & $\begin{array}{l}\text { AECOPD with severe respiratory } \\
\text { failure, pulmonary infection }\end{array}$ & Yes & $\begin{array}{l}\text { Bilevel NPPV delivered } \\
\text { by face mask }\end{array}$ \\
\hline Zhao and $\mathrm{Li}^{21}$ & 40 & 70 & $\begin{array}{l}\text { AECOPD with severe pulmonary } \\
\text { infection, respiratory failure }\end{array}$ & Yes & $\begin{array}{l}\text { Bilevel NPPV delivered } \\
\text { by face or nasal mask }\end{array}$ \\
\hline Zheng et $\mathrm{a}^{22}$ & 33 & 73 & $\begin{array}{l}\text { AECOPD with severe pulmonary } \\
\text { infection, respiratory failure }\end{array}$ & Yes & $\begin{array}{l}\text { Bilevel NPPV delivered } \\
\text { by face or nasal mask }\end{array}$ \\
\hline Zou et $\mathrm{al}^{23}$ & 76 & 71.5 & $\begin{array}{l}\text { AECOPD with severe respiratory } \\
\text { failure, pulmonary infection }\end{array}$ & Yes & $\begin{array}{l}\text { Bilevel NPPV delivered } \\
\text { by face or nasal mask }\end{array}$ \\
\hline
\end{tabular}

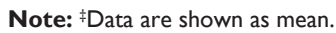

Abbreviations: NA, not available; AECOPD, acute exacerbation of chronic obstructive pulmonary disease; NPPV, noninvasive positive pressure ventilation.

of appropriate randomization methods, mainly computergenerated randomization lists (Figure S1).

\section{Primary outcomes}

\section{Mortality during hospital admission}

Fourteen studies evaluated whether the PIC window is a weaning strategy for reduced mortality. ${ }^{3,10-23}$ The metaanalysis associated it with significantly decreased mortality (RR $0.36,95 \%$ CI 0.23 to $0.57, P<0.00001 ; P^{2}=0 \%, P=0.989$ )

(Figure 2).

\section{VAP}

The proportion of participants developing VAP was reported in 16 trials involving 647 participants. ${ }^{3,9-23}$ The pooled estimate demonstrated a beneficial effect of the PIC window as a weaning strategy in reducing VAP (RR $0.28,95 \%$ CI 0.19 to $0.41, P<0.00001 ; P=0 \%, P=0.966$ ) (Figure 3).

\section{Secondary outcomes}

\section{Duration of MV}

Fifteen studies assessed mean duration of IMV. ${ }^{3,9-23}$ Pooled data using a random-effects model found strong evidence for the PIC window as a weaning strategy when compared to the conventional weaning strategy (WMD -7.68 days; $95 \%$ CI -9.43 to -5.93 days, $P<0.00001 ; I^{2}=98.1 \%, P=0.000$ ) (Figure 4). Twelve trials with 521 participants reported the total time of MV. ${ }^{3,9,11,13-23}$ The summary estimate found a significant decrease in the total time of MV (WMD -5.93 days; $95 \%$ CI -7.29 to -4.58 days, $P=0.000 ; I^{2}=98.3 \%$, $P=0.000$ ) (Figure 4).

\section{Length of ICU stay and hospital stay}

Ten trials involving 429 participants evaluated ICU length of stay. $3,10,14,17-23$ The PIC window provided a significant benefit toward shortening it (WMD -8.51 days, 95\% CI -10.23 


\begin{tabular}{|c|c|c|}
\hline Study ID & $\operatorname{RR}(95 \% \mathrm{Cl})$ & Weight \% \\
\hline Chen $^{10}$ & $0.42(0.13$ to 1.30$)$ & 12.83 \\
\hline Jiang and Jiang ${ }^{11}$ & $0.10(0.01$ to 1.69$)$ & 8.60 \\
\hline Li and Zhou ${ }^{12}$ & $0.37(0.04$ to 3.24$)$ & 4.39 \\
\hline Li et al ${ }^{13}$ & $0.50(0.05$ to 5.12$)$ & 3.07 \\
\hline Lin et al ${ }^{14}$ & $0.29(0.04$ to 2.39$)$ & 5.63 \\
\hline Lun et $\mathrm{al}^{15}$ & 0.55 (0.11 to 2.69$)$ & 5.84 \\
\hline Ning et $a^{16}$ & $0.19(0.01$ to 3.46$)$ & 4.55 \\
\hline Wang et $\mathrm{al}^{17}$ & 0.54 (0.06 to 5.24$)$ & 2.94 \\
\hline Wang $^{3}$ & $0.15(0.02$ to 1.16$)$ & 10.51 \\
\hline Wu et $a^{18}$ & $0.32(0.08$ to 1.29$)$ & 11.32 \\
\hline Zhang et al ${ }^{19}$ & $0.38(0.04$ to 3.25$)$ & 4.33 \\
\hline Zhang and Zhao et $\mathrm{al}^{20}$ & 0.54 (0.11 to 2.70$)$ & 5.90 \\
\hline Zheng et $\mathrm{al}^{22}$ & $0.95(0.22$ to 4.14$)$ & 4.72 \\
\hline Zou et $\mathrm{al}^{23}$ & $0.33(0.10$ to 1.09$)$ & 15.36 \\
\hline Overall $\left(I^{2}=0.0 \%, P=0.989\right)$ & $0.36(0.23$ to 0.57$)$ & 100 \\
\hline & $\mathrm{Cl} 0.23$ to $0.57, P<0.00001$ & \\
\hline
\end{tabular}

Figure 2 The effect of PIC window on mortality during hospital admission.

Abbreviations: PIC, pulmonary infection control; RR, risk ratio; $\mathrm{Cl}$, confidence interval.

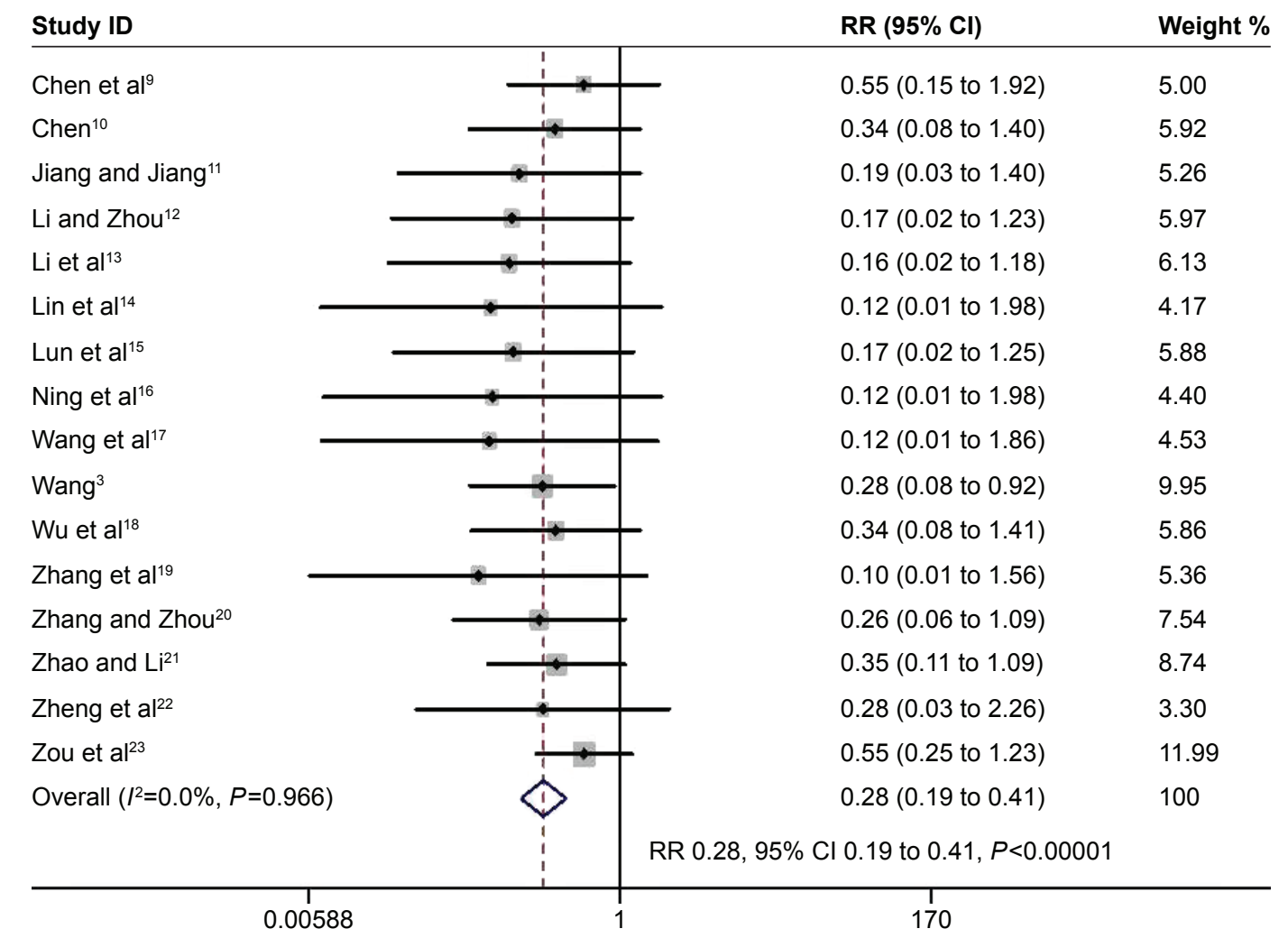

Figure 3 The effect of PIC window on VAP.

Abbreviations: PIC, pulmonary infection control; VAP, ventilator-associated pneumonia; RR, risk ratio; Cl, confidence interval. 


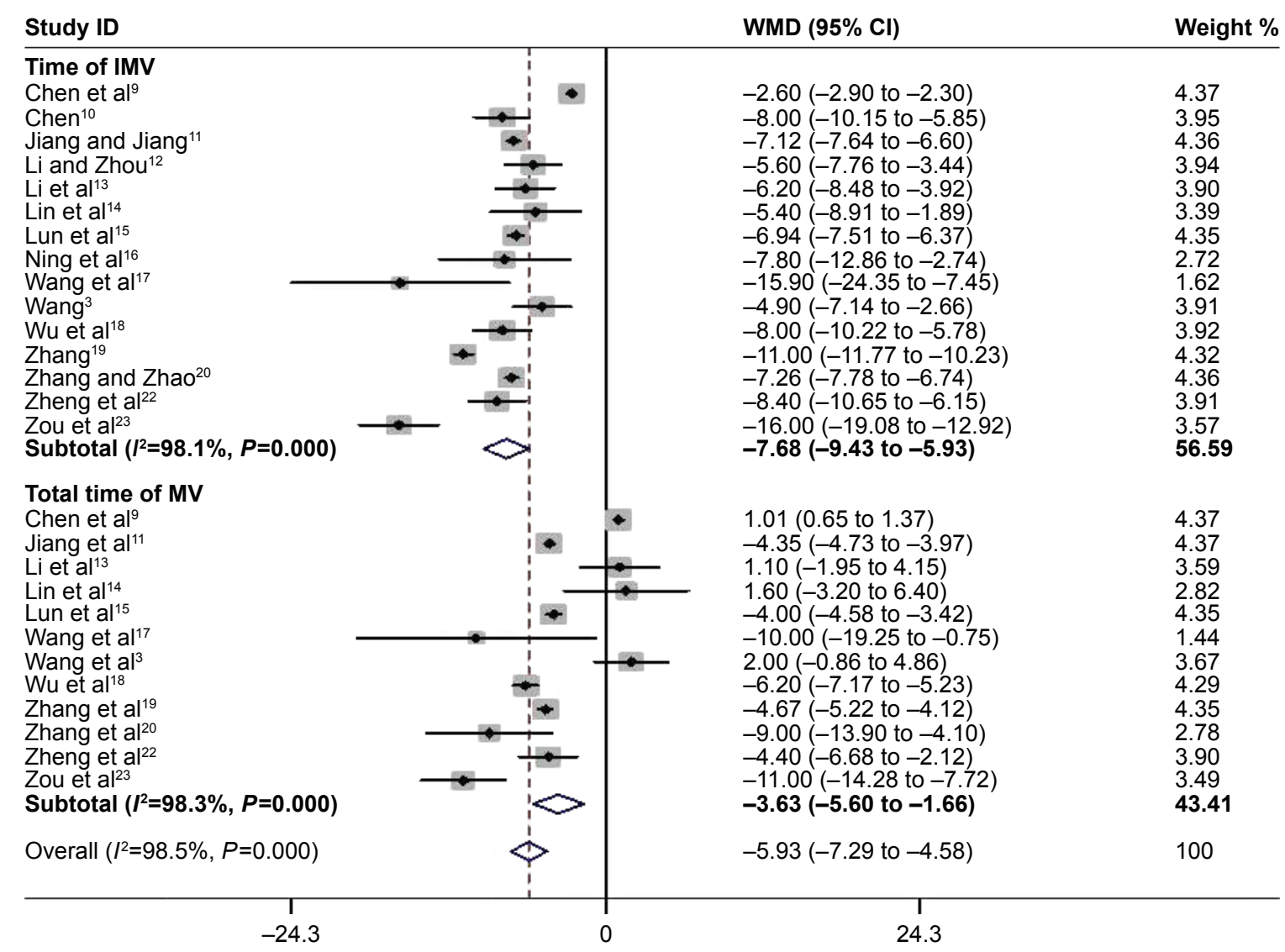

Figure 4 The effect of PIC window on duration of MV.

Note: Weights are from random effects analysis.

Abbreviations: PIC, pulmonary infection control; MV, mechanical ventilation; WMD, weighted mean difference; Cl, confidence interval; IMV, intermittent mandatory ventilation.

to -6.79 days, $\left.P=0.000 ; I^{2}=74.8 \%, P=0.000\right)$. Ten studies with 442 participants reported on the length of hospital stay. 3,9,12,14-16,18,20-23 Pooled data demonstrated a reduction in hospital stay, favoring the PIC window as a weaning strategy (WMD -8.47 days; $95 \% \mathrm{CI}-9.61$ to -7.33 days, $P<0.0001$; $\left.I^{2}=76.9 \%, P=0.000\right)$ (Figure 5).

\section{Adverse events associated with weaning}

The rate of reintubation was reported separately from the proportion of weaning failures in 11 trials with 478 participants..$^{3,9-13,17-23}$ The pooled estimate supported a significant reduction in reintubation rate with noninvasive weaning (RR $0.41,95 \%$ CI 0.27 to $0.63, P<0.0001 ; I^{2}=0 \%$, $P=0.96$ ) (Figure 6).

\section{Sensitivity analysis}

There was substantial heterogeneity in the continuous outcomes (duration of endotracheal mechanical intubation, total duration of MV, and length of ICU and hospital stay). Sensitivity analysis was performed to determine the source of heterogeneity (Figure S2). It was found that the study by Wang et al is a partial source of heterogeneity, ${ }^{3}$ mainly due to a larger sample size $(n=90)$ versus other studies. However, omitting this study did not significantly alter the pooled WMD values.

\section{Subgroup analysis}

To exclude the effect of confounding factors, such as risk of bias and disease severity, subgroup analysis was introduced. Subgroup analyses are summarized in Table S1, which found that the conclusions remained robust for methodological changes, demonstrating that data of the present study are reliable.

\section{Publication bias}

Publication bias was detected by Begg's and Egger's tests. Funnel plot of the studies evaluated primary outcomes (mortality and VAP), which appeared to be symmetrical through visual examination. The data suggested that there was no evidence of publication bias $(P>0.05)$ (Figure S3). 


\begin{tabular}{|c|c|c|}
\hline Study ID & WMD (95\% Cl) & Weight $\%$ \\
\hline \multicolumn{3}{|l|}{ Length of ICU stay } \\
\hline Chen $^{10}$ & $-10.00(-13.39$ to -6.61$)$ & 5.16 \\
\hline Lin et $\mathrm{al}^{14}$ & $-5.50(-10.51$ to -0.49$)$ & 3.35 \\
\hline Wang et $\mathrm{al}^{17}$ & $-13.00(-22.25$ to -3.75$)$ & 1.31 \\
\hline Wang $^{3}$ & $-4.00(-8.01$ to 0.01$)$ & 4.37 \\
\hline Wu et al $^{18}$ & $-10.00(-13.05$ to -6.95$)$ & 5.65 \\
\hline Zhang et $\mathrm{al}^{19}$ & $-9.00(-9.27$ to -8.73$)$ & 9.46 \\
\hline Zhang and Zhao ${ }^{20}$ & $-5.36(-7.59$ to -3.13$)$ & 6.97 \\
\hline Zhao and $\mathrm{Li}^{21}$ & $-12.00(-17.49$ to -6.51$)$ & 2.96 \\
\hline Zheng et $\mathrm{al}^{22}$ & $-6.00(-8.52$ to -3.48$)$ & 6.49 \\
\hline Zou et $\mathrm{al}^{23}$ & $-14.00(-17.15$ to -10.85$)$ & 5.51 \\
\hline Subtotal $\left(I^{2}=74.8 \%, P=0.000\right)$ & $-8.51(-10.23$ to -6.79$)$ & 51.23 \\
\hline \multicolumn{3}{|l|}{ Length of hospital stay } \\
\hline Chen et $\mathrm{al}^{9}$ & $-7.00(-9.93$ to -4.07$)$ & 5.84 \\
\hline $\mathrm{Li}$ and $\mathrm{Zhou}^{12}$ & $-9.60(-11.81$ to -7.39$)$ & 7.00 \\
\hline Lin et $\mathrm{al}^{14}$ & $-2.00(-15.05$ to 11.05$)$ & 0.71 \\
\hline Lun et $\mathrm{al}^{15}$ & $-6.31(-6.91$ to -5.71$)$ & 9.27 \\
\hline Ning et $\mathrm{al}^{16}$ & $-7.80(-13.83$ to -1.77$)$ & 2.59 \\
\hline$\longrightarrow$ & $-2.00(-7.32$ to 3.32$)$ & 3.10 \\
\hline Zhang et $\mathrm{al}^{19}$ & $-10.10(-12.27$ to -7.93$)$ & 7.06 \\
\hline Zhao and $\mathrm{Li}^{21}$ & $-13.00(-18.70$ to -7.30$)$ & 2.81 \\
\hline Zheng et $\mathrm{al}^{22}$ & $-8.00(-10.83$ to -5.17$)$ & 5.98 \\
\hline Zou et $\mathrm{al}^{23}$ & $-14.00(-17.97$ to -10.03$)$ & 4.41 \\
\hline Subtotal $\left(I^{2}=76.9 \%, P=0.000\right)$ & $-8.46(-10.35$ to -6.58$)$ & 48.77 \\
\hline Overall $\left(I^{2}=84.0 \%, P=0.000\right)$ & $-8.47(-9.61$ to -7.33$)$ & 100 \\
\hline $\begin{array}{c}1 \\
-22.2\end{array}$ & 22.2 & \\
\hline
\end{tabular}

Figure $\mathbf{5}$ The effect of PIC window on length of ICU stay and hospital stay.

Note: Weights are from random effects analysis.

Abbreviations: PIC, pulmonary infection control; ICU, intensive care unit; WMD, weighted mean difference; CI, confidence interval; ICU, intensive care unit.

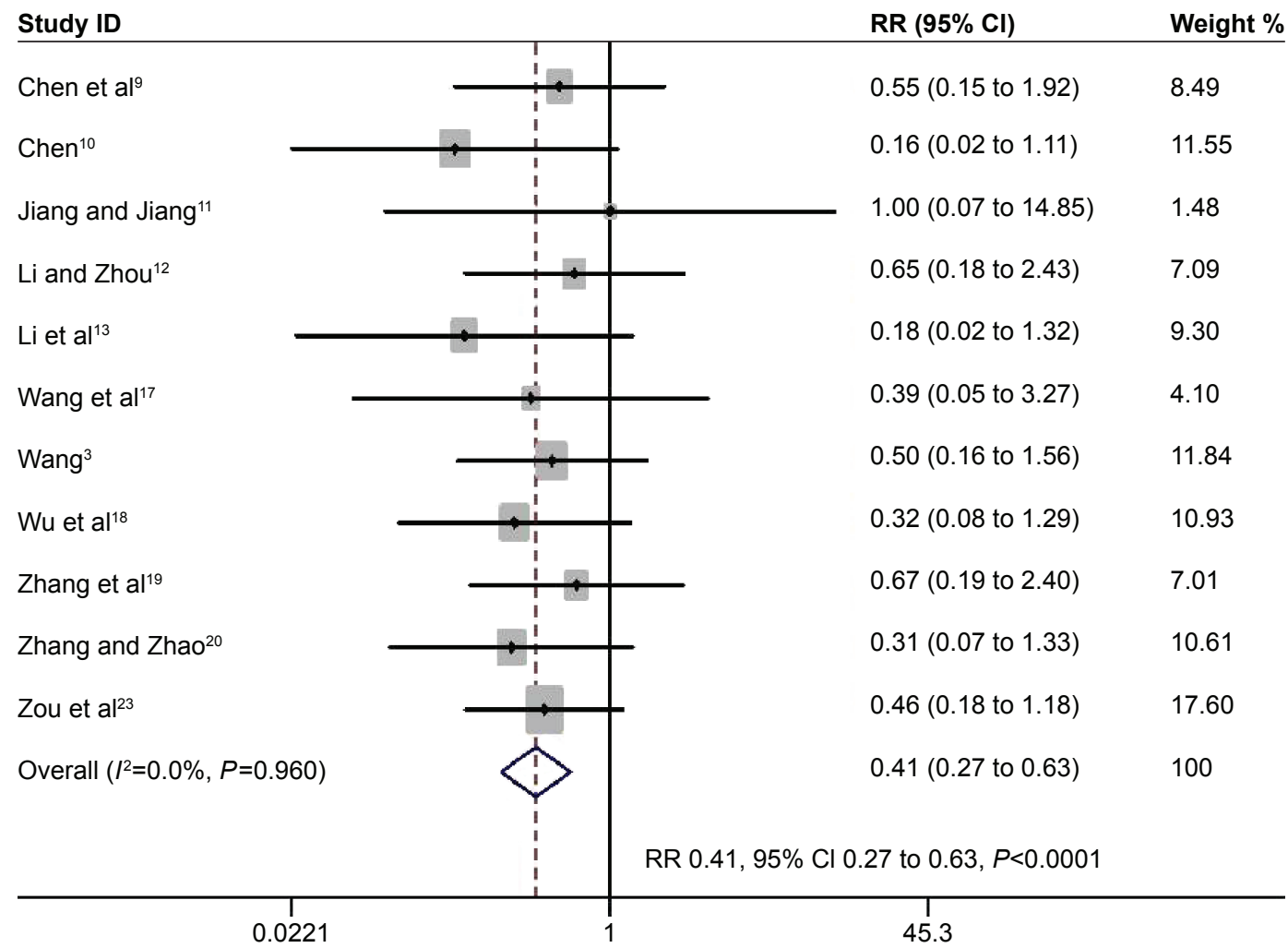

Figure 6 The effect of PIC window on adverse events associated with weaning. 


\section{Discussion}

This study identified 16 trials comparing the PIC window as a switch point for NPPV versus the conventional weaning strategy in patient treatment with respiratory failure due to COPD exacerbations. The PIC window weaning strategy showed significant improvement in mortality, VAP, length of ICU and hospital stay, and duration of MV compared to conventional weaning strategy. Together, the present data suggested that the PIC window might be a new tool for screening patients potentially ready to be extubated and immediately placed under NPPV.

Choosing an appropriate time to transfer from invasive ventilation (IV) to NIV is crucial in performing sequential MV successfully. ${ }^{24,25}$ The clinician's concern is optimum timing regarding the condition of the patient to wean from MV. Unfortunately, there is no consensus or relevant guidelines that yield a distinct conclusion. The PIC window has been defined as a prompt stage of controlled pulmonary infection following artificial airway establishment, sputum drainage, and antibiotic administration. ${ }^{1}$ Wang et al proposed this stage as the optimum timing to replace IV with NIV, so that ventilatory insufficiency and respiratory muscle fatigue might resolve, while lower airway infection and VAP were avoided. ${ }^{1}$ However, the PIC window for transitioning patients from MV to NIV for weaning has not been clearly established. According to this meta-analysis, it has been showed that the PIC window as a switching point for sequential ventilation may be beneficial for respiratory failure in COPD patients due to pulmonary infection. This may result in helpful information for clinicians to identify optimum timing for withdrawal.

The standard test for extubation readiness is the spontaneous breathing trial (SBT), performed by using the T-tube by disconnecting the patient from the ventilator and providing additional oxygen. ${ }^{26}$ Cabello et al compared 3 trial modalities before extubation in difficult-to-wean patients. They found that the patient effort was higher during a T-tube trial than during a pressure support trial. ${ }^{27}$ The number of patients who were extubated after 48 hours was similar when the weaning trial was performed with the T-tube or pressure support trial. ${ }^{28}$ Two studies have demonstrated that some patients who failed a T-tube trial could immediately succeed with a pressure support trial. ${ }^{27,29} \mathrm{SBT}$ is usually granted to patients who pass the weaning assessment. Despite its benefits among COPD patients, NIV should not be indicated for all patients failing SBT; they may be exposed to extubation failure due to substantial comorbidities. ${ }^{3}$ The main difference between the PIC widow weaning strategy and the SBT weaning strategy is optimal switching time to NPPV for further weaning in patients with COPD undergoing IPPV. The appearance of the PIC window indicates that pulmonary infections are under control. At this stage, drainage of airway secretions is minor, and the endotracheal tube may not be absolutely necessary, although respiratory muscle fatigue becomes relatively more significant in the development of respiratory failure. Thus, NPPV was continued to relieve fatigue of the respiratory muscle as well as ventilatory insufficiency. A recent study showed that in COPD patients with respiratory failure, weaning by SBT (assisted with NPPV) is suggested under insignificant pulmonary infection, while replacement by NPPV at the PIC window is encouraged for significant pulmonary infection. ${ }^{30}$ Thus, this window may serve as an alternative weaning tool in COPD patients with pulmonary infection. However, a comparison of data obtained from the application of NPPV at the PIC window or at SBT after meeting simple weaning criteria is still missing. ${ }^{31-35}$ Additional well-designed, adequately powered RCTs are needed to compare the efficacy of the PIC window weaning strategy with the SBT weaning strategy in treatment of COPD patients with respiratory failure.

\section{Limitations}

Several limitations of this study should be taken into account. First, due to substantial heterogeneity among studies reporting continuous outcomes (time of IMV, total time of MV, and length of ICU and hospital stay), caution must be used while interpreting these results. Second, in China, $~ 80 \%$ of COPD patients with exacerbations are due to pulmonary infection. ${ }^{3}$ This may be the main reason for the PIC window being used primarily. However, one should note that bronchial pulmonary infection accounted for $50 \%-70 \%$ of acute exacerbation of COPD occurrences worldwide. ${ }^{2}$ Thus, it may provide new insights for physicians considering the PIC window weaning strategy in other countries.

\section{Conclusion}

In summary, these data suggested that the PIC window reduced the need for intubation and mortality without increasing the risk of weaning failure in treatment of respiratory failure in COPD patients. It might not only yield relevant information for caregivers in China but also new insights for considering the PIC window by physicians in other countries.

\section{Disclosure}

The authors report no conflicts of interest in this work. 


\section{References}

1. GOLD Committee. Global Strategy for the Diagnosis, Management and Prevention of COPD, Global Initiative for Chronic Obstructive Lung Disease (GOLD); 2015. Available from: http://www.goldcopd. org/. Accessed November 20, 2015.

2. Zhong N, Wang C, Yao W, et al. Prevalence of chronic obstructive pulmonary disease in China: a large, population-based survey. Am J Respir Crit Care Med. 2007;176:753-760.

3. Wang C; Collaborating Research Group for Noninvasive Mechanical Ventilation of Chinese Respiratory Society. Pulmonary infection control window in treatment of severe respiratory failure of chronic obstructive pulmonary diseases: a prospective, randomized controlled, multi-centred study. Chin Med J. 2005;118:1589-1594.

4. Ladeira MT, Vital FM, Andriolo RB, Andriolo BN, Atallah AN, Peccin MS. Pressure support versus T-tube for weaning from mechanical ventilation in adults. Cochrane Database Syst Rev. 2014;5: CD006056.

5. Moher D, Liberati A, Tetzlaff J, et al. Preferred reporting items for systematic reviews and meta-analyses: the PRISMA statement. Open Med. 2009;3:e123-e130.

6. Vale CL, Tierney JF, Burdett S. Can trial quality be reliably assessed from published reports of cancer trials: evaluation of risk of bias assessments in systematic reviews. BMJ. 2013;346:f1798.

7. Higgins JP, Thompson SG, Deeks JJ, Altman DG. Measuring inconsistency in meta-analyses. BMJ. 2003;327:557-560.

8. Egger M, Davey Smith G, Schneider M, et al. Bias in meta-analysis detected by a simple, graphical test. BMJ. 1997;315:629-634 .

9. Chen H, Huang F, Liang YX. Applied research of invasive-noninvasive mechanical ventilation for chronic obstructive pulmonary disease complicating acute respiratory failure. Ling Nan J Emerg Med. 2010; 15:275-277.

10. Chen G. Effective of sequential non-invasive following short-term invasive mechanical ventilation (MV) on AECOPD patients. Med Innovat Res. 2008;5:9-10.

11. Jiang YP, Jiang LD. Research on bi-level noninvasive positive pressure ventilation in the treatment of invasive-noninvasive sequential ventilation. Mod Prev Med. 2008;35:1371-1375.

12. Li JH, Zhou ZX. Sequential non-invasive following short-term invasive mechanical ventilation in COPD patients with severe respiratory failure. Pract Geriatr. 2008;22:368-372.

13. Li JL, Chang SX, Lu CL, et al. Study on clinical application of bi-level positive airway pressure after removal of endotracheai intubation for Chronic Obstructive Pulmonary Disease complicated with type II respiratory failure. Clin Med China. 2012;28:712-714.

14. Lin WX, Yang JM, Lin Q. Sequential mechanical ventilation in patients with chronic obstructive pulmonary disease caused by severe respiratory failure. Shan Dong Med J. 2008;48:102-103.

15. Lun YH, Yan JW, Lin RP. Application of sequential non-invasive following short-term invasive mechanical ventilation in patients with AECOPD. Chinese J N Clin Med. 2009;2:144-148.

16. Ning K, Dong YC, Wang YT, et al. Value of the right time to the shift of invasive and noninvasive ventilation-clinical characteristics to the treatment of AECOPD with respiratory failure. Chinese J Gen Pract. 2010;8:711-712.

17. Wang C, Shang M, Huang K, et al. Sequential non-invasive mechanical ventilation following short-term invasive mechanical ventilation in COPD induced hypercapnic respiratory failure. Chin Med J (Engl). 2003;116:39-43.

18. Wu Q, Wang HX, Zheng SY, et al. Effect of sequential non-invasive following short-term invasive mechanical ventilation (MV) on patients with AECOPD. Appl J Gen Pract. 2007;5:945-949.
19. Zhang JX, Gao XL, Liu SH, et al. Analysis of sequential mechanical ventilation in chronic obstructive pulmonary disease patients with severe respiratory failure. Int J Respir. 2007;27:246-251.

20. Zhang XY, Zhao Y. Clinical research of sequential invasive-noninvasive mechanical ventilation in acute exacerbation of chronic obstructive pulmonary disease with respiratory failure. J Clin Pulm Med. 2012;17: 420-423.

21. Zhao JM, Li GX. Sequential non-invasive following short-term invasive mechanical ventilation initiated at the point of PIC window. Med $J$ West China. 2012;24:271-275.

22. Zheng RQ, Liu L, Yang Y, et al. Prospective randomized controlled clinical study of sequential non-invasive following invasive mechanical ventilation in patients with acute respiratory failure induced by COPD. Chinese J Emerg Med. 2005;14:21-29.

23. Zou SH, Zhou R, Chen P, et al. Application of sequential noninvasive following invasive mechanical ventilation in COPD patients with severe respiratory failure by investigating the appearance of pulmonaryinfection-control-window. Zhong Nan Da Xие Xие Bao Yi Xие Ban. 2006;31:120-124.

24. Burns KE, Meade MO, Premji A, et al. Noninvasive positive-pressure ventilation as a weaning strategy for intubated adults with respiratory failure. Cochrane Database Syst Rev. 2013;12:CD004127.

25. Nava S, Ambrosino N, Clini E, et al. Noninvasive mechanical ventilation in the weaning of patients with respiratory failure due to chronic obstructive pulmonary disease. Ann Intern Med. 1998;128:721-728.

26. Thille AW, Cortés-Puch I, Esteban A. Weaning from the ventilator and extubation in ICU. Curr Opin Crit Care. 2013;19:57-64.

27. Cabello B, Thille AW, Roche-Campo F, et al. Physiological comparison of three spontaneous breathing trials in difficult-to-wean patients. Intensive Care Med. 2010;36:1171-1179.

28. Esteban A, Alia I, Gordo F, et al. Extubation outcome after spontaneous breathing trials with $\mathrm{T}$-tube or pressure support ventilation. The Spanish Lung Failure Collaborative Group. Am J Respir Crit Care Med. 1997;156:459-465.

29. Ezingeard E, Diconne E, Guyomarc'h S, et al. Weaning from mechanical ventilation with pressure support in patients failing a $\mathrm{T}$-tube trial of spontaneous breathing. Intensive Care Med. 2006;32:165-169.

30. Song Y, Chen R, Zhan Q, et al. The optimum timing to wean invasive ventilation for patients with AECOPD or COPD with pulmonary infection. Int J Chron Obstruct Pulmon Dis. 2016;11:535-542.

31. Ram FS, Picot J, Lightowler J, Wedzicha JA. Non-invasive positive pressure ventilation for treatment of respiratory failure due to exacerbations of chronic obstructive pulmonary disease. Cochrane Database Syst Rev. 2004;1:CD004104.

32. Yan HY, Yang Y, Wu YL. Clinical analysis of optimal timing for application of noninvasive positive pressure ventilation in treatment of AECOPD patients. Eur Rev Med Pharmacol Sci. 2014;18: 2176-2181.

33. Reddy RM, Guntupalli KK. Review of ventilatory techniques to optimize mechanical ventilation in acute exacerbation of chronic obstructive pulmonary disease. Int J Chron Obstruct Pulmon Dis. 2007; 2:441-452.

34. Rose L, Schultz MJ, Cardwell CR, et al. Automated versus nonautomated weaning for reducing the duration of mechanical ventilation for critically ill adults and children (review). Cochrane Database Syst Rev. 2014;6:CD009235.

35. Ladeira MT, Vital FM, Andriolo RB, et al. Pressure support versus T-tube for weaning from mechanical ventilation in adults. Cochrane Database Syst Rev. 2014;5:CD006056. 


\section{Supplementary materials}

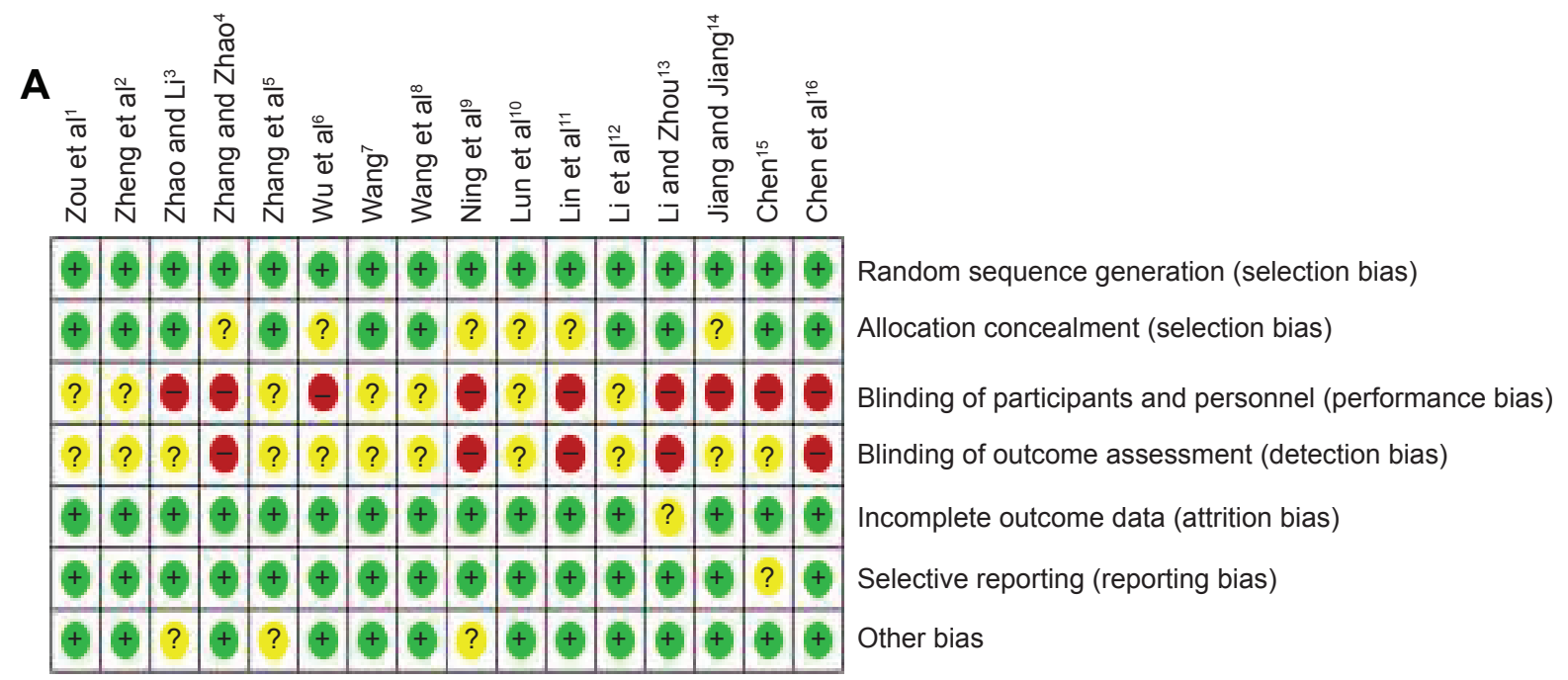

B

Random sequence generation (selection bias) Allocation concealment (selection bias) Blinding of participants and personnel (performance bias)

Blinding of outcome assessment (detection bias) Incomplete outcome data (attrition bias)

Selective reporting (reporting bias)

Other bias

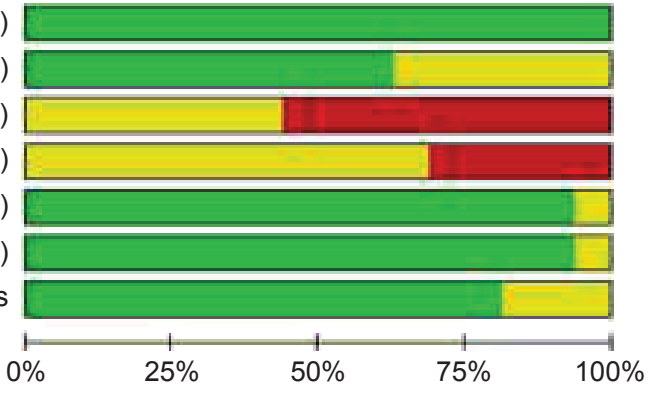

Low risk of bias

Unclear risk of bias

High risk of bias

Figure SI Risk of bias analysis.

Notes: (A) Risk-of-bias summary: the authors' judgments about each risk-of-bias item for the each included studies. (B) Risk-of-bias graph: the authors' judgments about each risk-of-bias item presented as percentages across all included studies. 

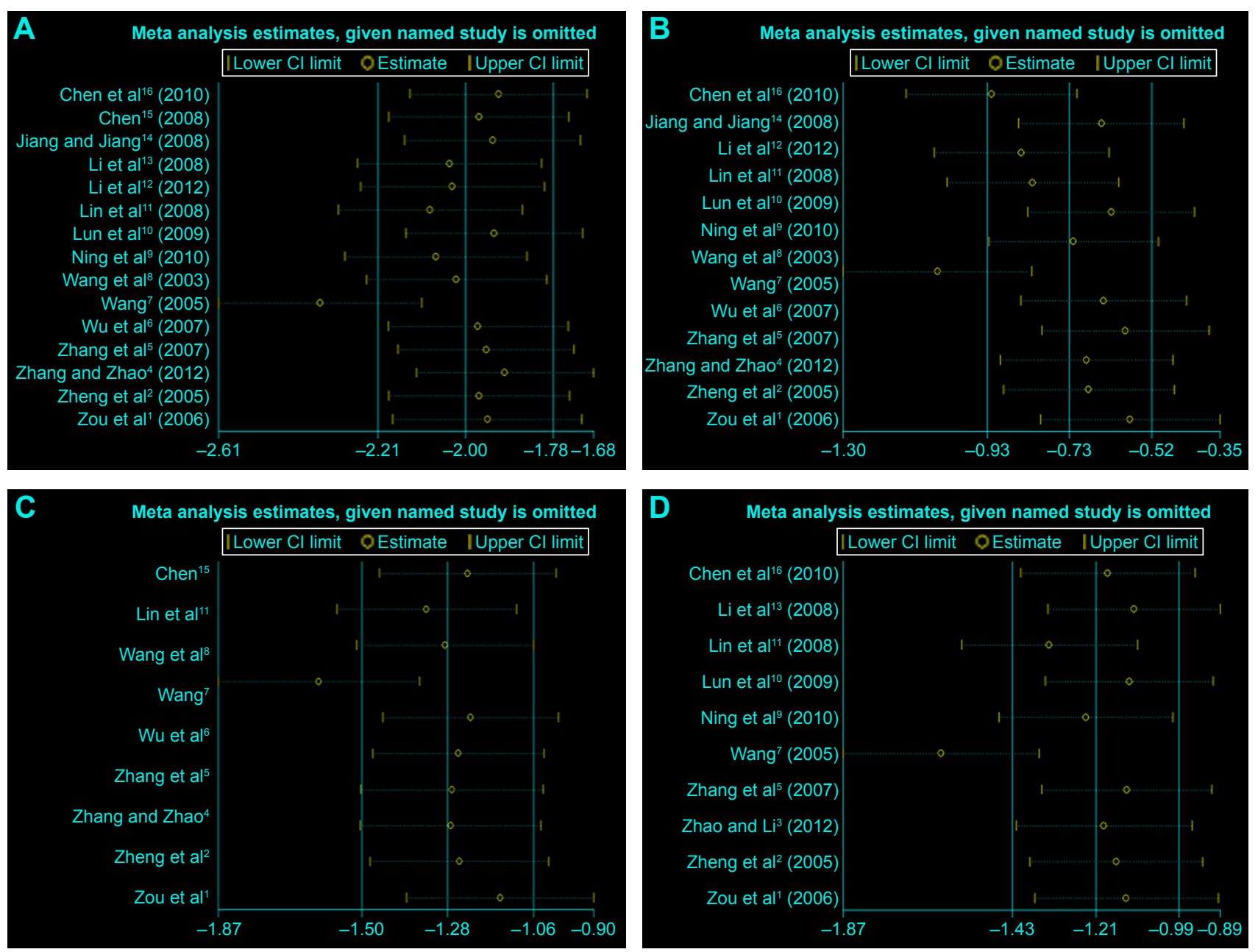

Figure S2 Sensitivity analysis.

Notes: (A) Time of IMV. (B) Total time of MV. (C) Length of ICU stay. (D) Length of hospital stay.

Abbreviations: IMV, intermittent mandatory ventilation; MV, mandatory ventilation; ICU, intensive care unit; $\mathrm{Cl}$, confidence interval.
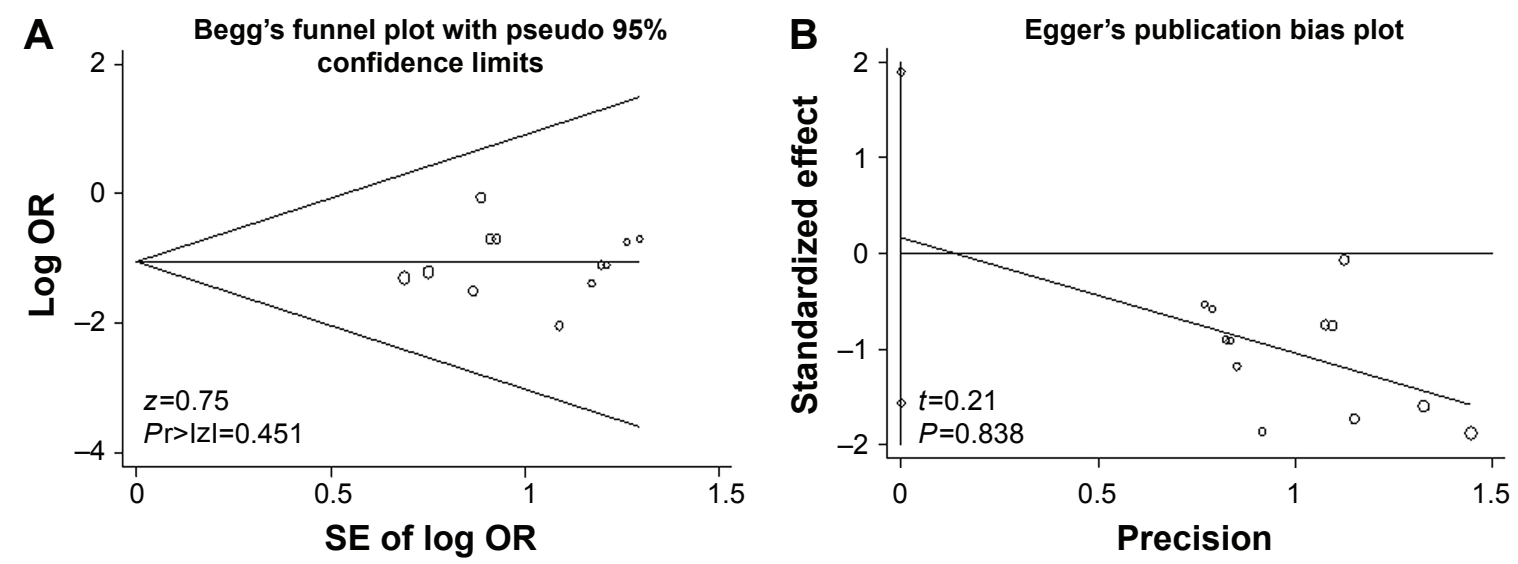

Figure S3 (Continued) 


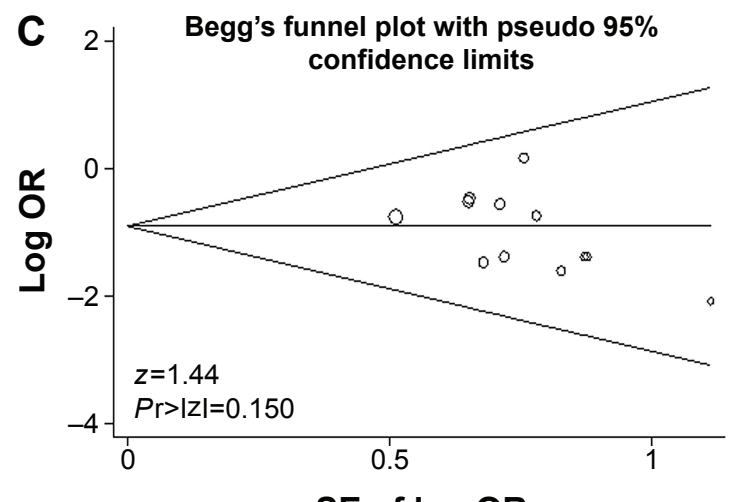

SE of $\log$ OR

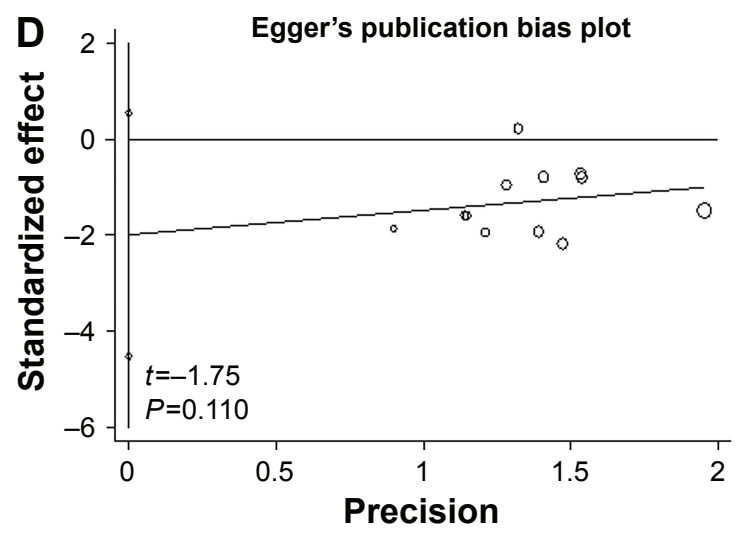

Figure S3 Publication bias.

Notes: The primary outcomes mortality $(\mathbf{A}$ and $\mathbf{B})$ and ventilator-associated pneumonia $(\mathbf{C}$ and $\mathbf{D})$ were detected by Begg's and Egger's tests.

Abbreviations: SE, standard error; OR, odds ratio.

Table SI Results of subgroup analyses from a meta-analyses of randomized controlled trials

\begin{tabular}{|c|c|c|c|c|c|}
\hline \multirow[t]{2}{*}{ Trials } & Mortality $^{2-15}$ & VAP $^{2-16}$ & Time of IMV $2-16$ & Hospital stay $2-4,6,7,9-11,13,16$ & Adverse events ${ }^{2-8,12-16}$ \\
\hline & \multicolumn{5}{|c|}{ RR or WMD (95\% Cl), $P$-value } \\
\hline \multirow[t]{3}{*}{ All trials ${ }^{2-16}$} & RR 0.36 & RR 0.28 & WMD -7.68 & WMD -8.46 & RR 0.4I \\
\hline & $(0.23,0.57)$ & $(0.19,0.4 I)$ & $(-9.43,-5.93)$ & $(-10.35,-6.58)$ & $(0.27,0.63)$ \\
\hline & $<0.00001$ & $<0.00001$ & $<0.0000 \mathrm{I}$ & $<0.0001$ & $<0.0001$ \\
\hline \multicolumn{6}{|l|}{ Subgroup analyses } \\
\hline \multicolumn{6}{|l|}{ Risk of bias } \\
\hline \multirow[t]{2}{*}{$\operatorname{Low}^{2-4,6-8,10,12,14,15}$} & $0.36(0.22,0.60)$ & $0.25(0.11,0.54)$ & $-8.54(-10.01,7.07)$ & $-8.80(-11.52,-6.07)$ & $0.39(0.23,0.64)$ \\
\hline & $<0.0001$ & $=0.000$ & $=0.000$ & $=0.000$ & $=0.000$ \\
\hline \multirow[t]{2}{*}{$\mathrm{High}^{5,9,11,13,16}$} & $0.36(0.23,0.57)$ & $0.29(0.19,0.45)$ & $-5.56(-8.57,-2.55)$ & $-8.48(-10.16,-6.80)$ & $0.48(0.22,1.03)$ \\
\hline & $=0.04 \mathrm{I}$ & $=0.000$ & $=0.000$ & $=0.000$ & $=0.50$ \\
\hline \multicolumn{6}{|l|}{ Sample size (n) } \\
\hline \multirow[t]{2}{*}{$\leq 40^{3,4,6-11,13,15,16}$} & $0.42(0.24,0.74)$ & $0.25(0.15,0.42)$ & $-7.54(-10.18,-4.90)$ & $-8.33(-10.07,-6.58)$ & $0.42(0.23,0.76)$ \\
\hline & $=0.003$ & $=0.000$ & $=0.000$ & $=0.000$ & $=0.003$ \\
\hline \multirow[t]{2}{*}{$>40^{2,5,7,7,12,14}$} & $0.28(0.13,0.6 \mathrm{I})$ & $0.32(0.19,0.56)$ & $-7.72(-9.16,-6.29)$ & $-8.14(-19.89,3.62)$ & $0.40(0.22,0.73)$ \\
\hline & $=0.001$ & $=0.000$ & $=0.000$ & $=0.040$ & $=0.004$ \\
\hline \multicolumn{6}{|c|}{ Disease severity (respiratory failure) } \\
\hline \multirow[t]{2}{*}{ Moderate ${ }^{7-10,13,15,16}$} & $0.39(0.20,0.76)$ & $0.25(0.13,0.46)$ & $-6.91(-9.46,-4.37)$ & $-8.13(-10.15,-6.10)$ & $0.35(0.18,0.65)$ \\
\hline & $=0.006$ & $=0.000$ & $=0.000$ & $=0.000$ & $=0.001$ \\
\hline \multirow[t]{2}{*}{ Severe ${ }^{2-7,11,12,14}$} & $0.34(0.19,0.63)$ & $0.30(0.19,0.49)$ & $-8.22(-9.80,-5.93)$ & $-8.68(-13.20,-4.16)$ & $0.48(0.27,0.85)$ \\
\hline & $=0.00 \mathrm{I}$ & $=0.000$ & $=0.000$ & $=0.000$ & $=0.011$ \\
\hline \multicolumn{6}{|c|}{ Experimental strategy } \\
\hline \multirow[t]{2}{*}{ Face mask ${ }^{5-10,13-16}$} & $0.33(0.19,0.58)$ & $0.24(0.15,0.40)$ & $-7.40(-9.58,-5.55)$ & $-7.57(-9.56,-5.58)$ & $0.43(0.27,0.70)$ \\
\hline & $=0.000$ & $=0.000$ & $=0.000$ & $=0.000$ & $=0.001$ \\
\hline \multirow[t]{2}{*}{ Face/nasal mask ${ }^{2-4,11,12}$} & $0.44(0.20,0.96)$ & $0.35(0.20,0.63)$ & $-8.54(-12.09,-4.99)$ & $-10.58(-14.75,6.42)$ & $0.36(0.15,0.64)$ \\
\hline & $=0.040$ & $=0.000$ & $=0.000$ & $=0.000$ & $=0.019$ \\
\hline \multicolumn{6}{|l|}{ Control strategy } \\
\hline \multirow[t]{2}{*}{$\mathrm{SIMV}+\mathrm{PS}^{3-7,9,13-15}$} & $0.34(0.20,0.6 \mathrm{I})$ & $0.29(0.15,0.56)$ & $-7.60(-9.00,-6.21)$ & $-8.82(-11.09,-6.55)$ & $0.42(0.24,0.72)$ \\
\hline & $=0.000$ & $=0.000$ & $=0.000$ & $=0.000$ & $=0.002$ \\
\hline \multirow[t]{2}{*}{$\mathrm{AC} / \mathrm{SIMV}+\mathrm{PS}^{2,8,10-12,16}$} & $0.40(0.18,0.85)$ & $0.27(0.17,0.44)$ & $-8.90(-11.51,-6.29)$ & $-8.15(-11.17,-5.14)$ & $0.40(0.21,0.79)$ \\
\hline & $=0.018$ & $=0.000$ & $=0.000$ & $=0.000$ & $=0.008$ \\
\hline
\end{tabular}

Abbreviations: RR, relative risk; WMD, weighted mean difference; $\mathrm{Cl}$, confidential interval; VAP, ventilator-associated pneumonia; IMV, intermittent mandatory ventilation; AC, assisted/controlled ventilation; SIMV, synchronized intermittent mandatory ventilation; PS, pressure support. 


\section{References}

1. Zou SH, Zhou R, Chen P, et al. Application of sequential noninvasive following invasive mechanical ventilation in COPD patients with severe respiratory failure by investigating the appearance of pulmonaryinfection-control-window. Zhong Nan DaXueXueBao Yi Xue Ban. 2006:31:120-124.

2. Zheng RQ, Liu L, Yang Y, et al. Prospective randomized controlled clinical study of sequential non-invasive following invasive mechanical ventilation in patients with acute respiratory failure induced by COPD. Chinese J Emerg Med. 2005;14:21-29.

3. Zhao JM, Li GX. Sequential non-invasive following short-term invasive mechanical ventilation initiated at the point of PIC window. Med J West China. 2012;24:271-275.

4. Zhang XY, Zhao Y. Clinical research of sequential invasive-noninvasive mechanical ventilation in acute exacerbation of chronic obstructive pulmonary disease with respiratory failure. J ClinPulm Med. 2012;17:420-423.

5. Zhang JX, Gao XL, Liu SH, et al. Analysis of sequential mechanical ventilation in chronic obstructive pulmonary disease patients with severe respiratory failure. Int J Respir. 2007;27:246-251.

6. Wu Q, Wang HX, Zheng SY, et al. Effect of sequential non-invasive following short-term invasive mechanical ventilation (MV) on patients with AECOPD. Appl J Gen Pract. 2007;5:945-949.

7. Wang C; Collaborating Research Group for Noninvasive Mechanical Ventilation of Chinese Respiratory Society. Pulmonary infection control window in treatment of severe respiratory failure of chronic obstructive pulmonary diseases: a prospective, randomized controlled, multi-centred study. Chin Med J. 2005;118:1589-1594.

8. Wang C, Shang M, Huang K, et al. Sequential non-invasive mechanical ventilation following short-term invasive mechanical ventilation in COPD induced hypercapnic respiratory failure. Chin Med J (Engl). 2003;116:39-43.
9. Ning K, Dong YC, Wang YT, et al. Value of the right time to the shift of invasive and noninvasive ventilation-clinical characteristics to the treatment of AECOPD with respiratory failure. Chinese J Gen Pract. 2010;8:711-712.

10. Lun YH, Yan JW, Lin RP. Application of sequential non-invasive following short-term invasive mechanical ventilation in patients with AECOPD. Chinese J N Clin Med. 2009;2:144-148.

11. Lin WX, Yang JM, Lin Q. Sequential mechanical ventilation in patients with chronic obstructive pulmonary disease caused by severe respiratory failure. Shan Dong Med J. 2008;48:102-103.

12. Li JL, Chang SX, Lu CL, et al. Study on clinical application of bi-level positive airway pressure after removal of endotracheai intubation for Chronic Obstructive Pulmonary Disease complicated with type II respiratory failure. Clin Med China. 2012;28:712-714.

13. Li JH, Zhou ZX. Sequential non-invasive following short-term invasive mechanical ventilation in COPD patients with severe respiratory failure. PractGeriatr. 2008;22:368-372.

14. Jiang YP, Jiang LD. Research on bi-level noninvasive positive pressure ventilation in the treatment of invasive-noninvasive sequential ventilation. Mod Prev Med. 2008;35:1371-1375.

15. Chen G. Effective of sequential non-invasive following short-term invasive mechanical ventilation (MV) on AECOPD patients. Med Innovat Res. 2008;5:9-10.

16. Chen H, Huang F, Liang YX. Applied research of invasive-noninvasive mechanical ventilation for chronic obstructive pulmonary disease complicating acute respiratory failure. Ling Nan J Emerg Med. 2010;15:275-277.
International Journal of COPD

\section{Publish your work in this journal}

The International Journal of COPD is an international, peer-reviewed journal of therapeutics and pharmacology focusing on concise rapid reporting of clinical studies and reviews in COPD. Special focus is given to the pathophysiological processes underlying the disease, intervention programs, patient focused education, and self management protocols.

\section{Dovepress}

This journal is indexed on PubMed Central, MedLine and CAS. The manuscript management system is completely online and includes a very quick and fair peer-review system, which is all easy to use. Visit http://www.dovepress.com/testimonials.php to read real quotes from published authors. 